\title{
Lymphatic Invasion is an Independent Adverse Prognostic Factor in Patients with Colorectal Liver Metastasis
}

\author{
Jannemarie A. M. de Ridder, MD ${ }^{1}$, Nikki Knijn, $\mathrm{MD}^{2}$, Bastiaan Wiering, MD, $\mathrm{PhD}^{3}$, Johannes H. W. de Wilt, MD, \\ $\mathbf{P h D}^{1}$, and Iris $\mathrm{D}$. Nagtegaal, $\mathrm{MD}, \mathbf{P h D}^{2}$ \\ ${ }^{1}$ Department of Surgical Oncology, Radboud University Medical Center, Nijmegen, The Netherlands; ${ }^{2}$ Department of \\ Pathology, Radboud University Medical Center, Nijmegen, The Netherlands; ${ }^{3}$ Department of Surgery, Slingeland Hospital, \\ Doetinchem, The Netherlands
}

\begin{abstract}
Background. For a selection of patients with colorectal liver metastases (CRLM), liver resection is a curative option. In order to predict long-term survival, clinicopathologic risk scores have been developed, but little is known about histologic factors and their prognostic value for disease-free and overall survival. The objective of the present study was to assess possible prognostic histologic factors in patients with solitary CRLM treated with liver resection who did not receive neoadjuvant treatment.
\end{abstract}

Methods. Patients with solitary CRLM who underwent liver resection between 1992 and 2011 were evaluated for clinical prognostic factors. Histologic analyses on tumor thickness at the tumor-normal interface, presence of a fibrotic capsule, intrahepatic vascular invasion, lymphatic invasion, or bile duct invasion and perineural growth were performed, using immunohistochemistry.

Results. A total of 124 patients were analyzed with a median follow-up of 41 months (range 1-232 months). There was no association between histologic factors and disease-free survival in multivariate analysis. In multivariate analysis, intrahepatic lymphatic invasion was associated with a decreased overall survival (41.9 vs.

Electronic supplementary material The online version of this article (doi:10.1245/s10434-015-4562-8) contains supplementary material, which is available to authorized users.

(C) The Author(s) 2015. This article is published with open access at Springerlink.com

First Received: 22 October 2014;

Published Online: 19 May 2015

J. A. M. de Ridder, MD

e-mail: Jannemarie.deridder@ radboudumc.nl
61.0 months; $p=0.041)$, especially in combination with vascular invasion $(n=15) \quad(28.1 \quad$ vs. 62.2 months; $p<0.0001)$. In addition, size over $50 \mathrm{~mm}(29.2$ vs. 65.9 months; $p=0.004$ ) and interval less than 12 months between resection of the primary tumor and diagnosis of liver metastasis (49.0 vs. 91.5 months: $p=0.019$ ) were also independent adverse prognostic factors.

Conclusions. Intrahepatic lymphatic invasion, especially in combination with vascular invasion, is an important adverse prognostic factor for overall survival in patients with solitary CRLM after liver resection.

Colorectal cancer is one of the leading causes of cancer death worldwide as a result of its considerable risk of development of metastases. ${ }^{1}$ When metastatic disease is confined to the liver, partial liver resection is the only curative therapeutic option, with 5-year overall survival (OS) percentages between 20 and $60 \%$, depending on patient and tumor characteristics. ${ }^{2-4}$ In order to explain these varying survival rates, different clinicopathologic risk scores have been developed. In many of these risk scores, nodal status of the primary tumor, size and number of the colorectal liver metastases (CRLM), disease-free interval from treatment of the primary until detection of the CRLM, and preoperative level of carcinoembryonic antigen (CEA) are combined to predict long-term survival. ${ }^{5-9}$ These scoring systems are relevant with respect to prediction of survival, but to our knowledge, they have not been used for risk stratification in controversial areas such as the administration of neoadjuvant or adjuvant systemic therapy or surveillance.

In primary colorectal cancer histologic factors such as extramural venous invasion, perineural growth, lymphatic 
invasion, angioinvasion, and diffuse growth pattern have been associated with poorer survival outcomes. ${ }^{10,11}$ Extramural venous invasion in particular is considered a poor prognostic factor, and as a result, patients with extramural venous invasion in stage II colon cancer are considered candidates for adjuvant systemic treatment. ${ }^{12}$ Very little is known about the impact of histologic features of colorectal liver metastases on OS, as described in a recent review. ${ }^{13}$

Vascular invasion, bile duct invasion, or lymphatic invasion by tumor cells in CRLM have all been suggested as prognostic factors for long-term survival. ${ }^{5,14-23}$ Perineural growth, the presence of a fibrous capsule, and tumor thickness at the tumor-normal interface have also been linked to survival in patients with CRLM. ${ }^{14,15,19,24-26}$ Variations in definitions and selection of patients have limited the impact of these studies. Furthermore, none of these previous studies has evaluated multiple histologic factors of the liver resection specimens, in combination with established risk scores in a homogenous group of patients. Most studies included patients who underwent neoadjuvant therapy as well as chemotherapy-naive patients, patients with multiple liver metastases, or patients with extrahepatic disease. ${ }^{5,14-21,23,24}$ The results of these previous studies might be biased because of the known changes in histologic features observed in liver metastases after systemic therapy, and the possible heterogeneous nature of multiple metastases. ${ }^{27-30}$

The objective of the current study was to assess possible prognostic histologic factors for long-term survival in patients with solitary colorectal liver metastases who underwent a complete (R0) liver without neoadjuvant systemic therapy.

\section{MATERIALS AND METHODS}

\section{Patients}

Patients were identified who underwent complete (R0) liver resection for a solitary CRLM between 1992 and 2011 in a tertiary referral hospital. R0 resections were defined as liver resections with clear resection margins in patients who did not have evidence of disease in any other locations. Demographics and clinicopathologic factors with regard to the primary tumor, as well as the liver metastasis, were collected per patient. Special attention was given to the four different items from the clinical risk score according to Fong et al.: nodal status of the primary tumor; preoperative CEA level and size of the metastasis, and interval between resection of the primary tumor and diagnosis of CRLM. ${ }^{9}$ It is unknown whether systemic treatment influences the presence of certain histopathology factors and therefore patients who were treated with neoadjuvant systemic therapy were excluded from the current study.
Patients who died from postoperative complications, defined as within 30 days after liver resection, were also excluded. Patients underwent follow-up according to our current Dutch follow-up guidelines, with regular outpatient visits, CEA testing and computed tomographic scans of chest and abdomen.

\section{Histopathology}

R0 liver resection specimens with a solitary CRLM were selected from the archive. Routine workup consisted of sampling of macroscopically normal liver tissue, invasive front of the metastasis, and additional tumor blocks, depending on the size of metastasis. Slide revision was performed independently by two investigators (JdR, NK). Discrepancies were resolved by simultaneous reexamination of the slides by both investigators using a two-headed microscope. In case of discrepancy, the senior pathologist (IN) made the final call.

Tumor thickness at the tumor-normal interface was determined in routine slides. Tumor-normal interface was defined as the interface between tumor and normal liver tissue, as described by Maru et al. and validated by others. $^{26,31,32}$ In all tumors, tumor thickness was measured with a ruler at multiple foci, and maximum tumor thickness was used and defined as uninterrupted layers of tumor cells without admixed fibrotic stroma, acellular mucin, or nonneoplastic liver parenchyma. The median tumor thickness at tumor-normal interface was used to divide the patient group in a group with a larger and a smaller layer of vital tumor cells (Fig. 1).

The presence of a fibrotic capsule around the metastasis was evaluated in routine slides. The fibrous tissue between tumors and liver parenchyma was classified as absent (no

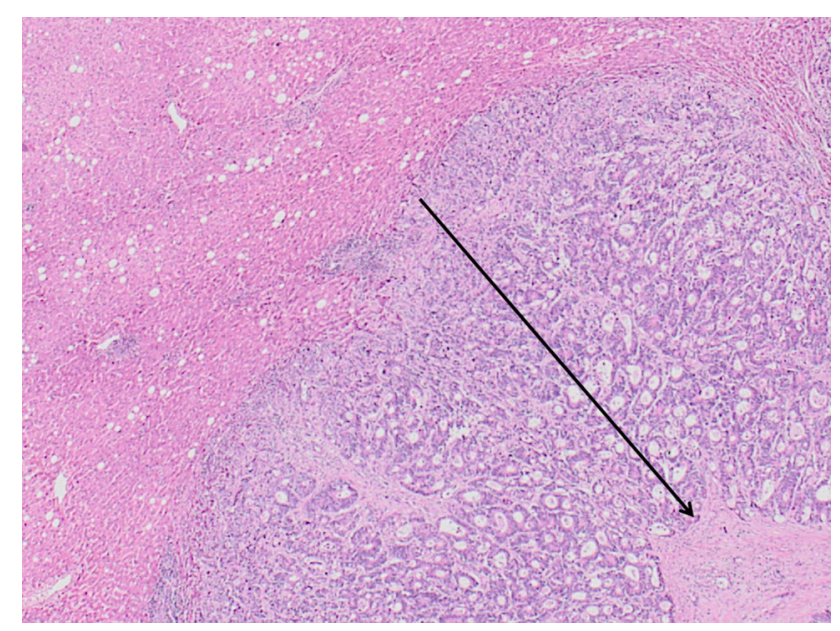

FIG. 1 Tumor thickness at tumor-normal interface; arrow indicates correct measurement with uninterrupted layer of tumor cells. Original magnification, $\times 10$ 
fibrous tissue observed) or present: tumor was separated from the liver parenchyma by several layers of collagen bundles in histologic sections (Fig. 2).

\section{Immunohistochemistry and Scoring Methods}

Immunohistochemistry was performed as previously described. ${ }^{33}$ Antibodies, clones, dilution, and retrieval methods are summarized in Supplementary Table 1.

Perineural growth was defined as a nerve, identified by S-100 staining, being surrounded by tumor cells for at least three quarters of the circumference and was scored as being present or absent (Fig. 3a).

Lymphatic invasion was defined as single tumor cells or cell clusters visible within vessels that showed immunoreactivity for D2-40 but not for CD31. Lymphatic invasion was scored as being present or absent (Fig. 3b).

Vascular invasion was defined as single tumor cells or cell clusters visible within vessels that showed immunoreactivity

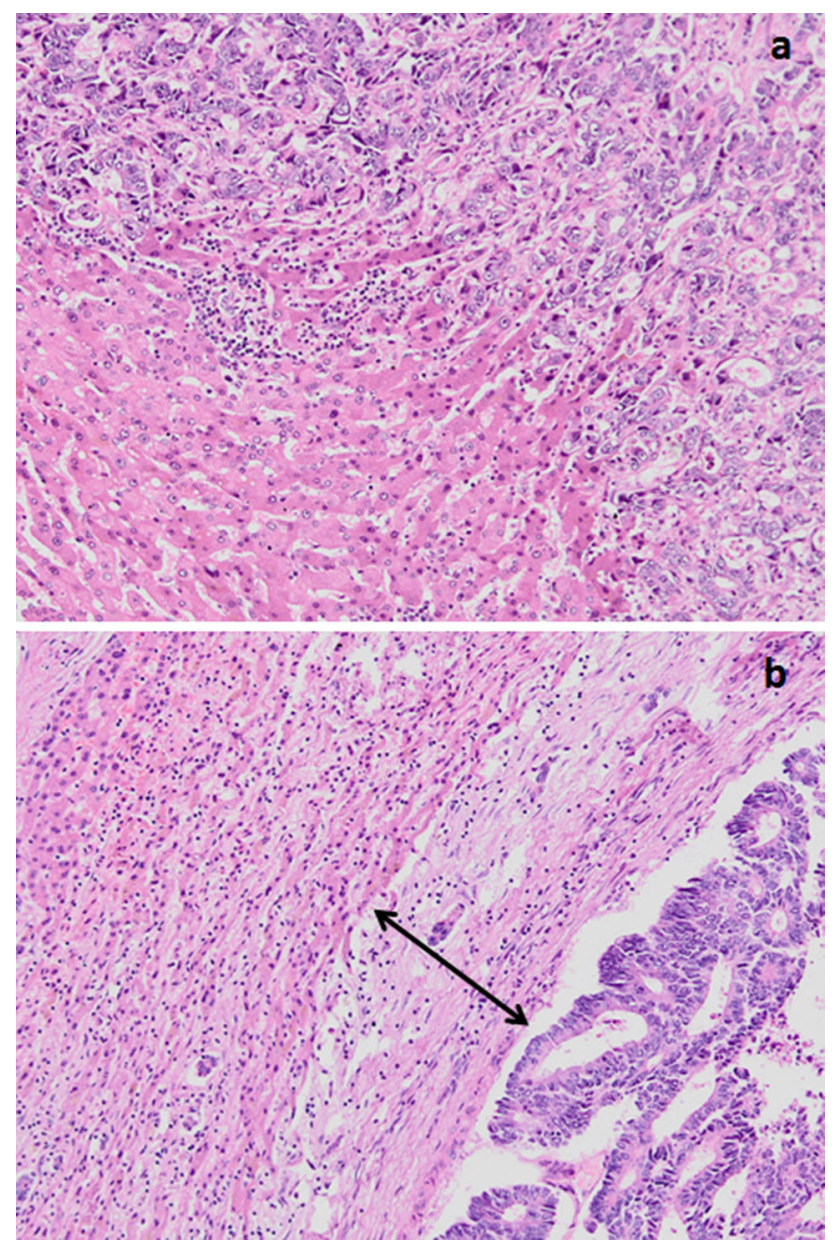

FIG. 2 a Colorectal liver metastasis without fibrous capsule. Original magnification, $\times 20$. b Colorectal liver metastasis with fibrous capsule (arrow). Original magnification, $\times 20$ for $\mathrm{CD} 31$ but not for D2-40. It was scored as being present or absent (Fig. 3c).

Bile duct invasion was defined as single tumor cells or cell clusters (CK7 negative) visible within bile ducts that showed immunoreactivity for CK7. It was also scored as being present or absent (Fig. 3d).

\section{Outcome}

Primary outcomes were disease-free survival (DFS) and OS. DFS was defined as the interval in months between liver resection and disease recurrence, death, or last follow-up. OS was defined as the interval in months between liver resection and death or date of last followup.

\section{Statistical Analysis}

Pearson's Chi square test was used to calculate correlations between the various histologic features. Survival curves were estimated by the Kaplan-Meier method and compared by log rank testing. Multivariate analysis was performed using Cox proportional hazard model, and variables were included that were associated with survival in univariate analysis with a $p$ value of $<0.10$. SPSS statistical software, version 18.0 (IBM, Armonk, NY, USA) was used for all statistical analysis. A $p$ value of $<0.05$ was considered statistically significant.

\section{RESULTS}

\section{Patients}

Between January 1992 and March 2011, a total of 383 patients underwent liver resection for metastatic disease. After excluding patients with multiple metastases, 135 patients remained who were surgically treated (R0) for solitary CRLM. Eleven patients were excluded because they received neoadjuvant chemotherapy $(n=5)$, were lost to follow-up $(n=2)$, or died within 30 days after liver resection $(n=4)$. A total of 124 patients were eligible to be included in the current study, 76 men $(61.3 \%)$ and 48 women (38.7\%). Median age at time of resection was 64 years (range 40-80 years). Liver metastasis were detected at a median of 8.8 months (range 0-82 months) after resection of the primary tumor. Median size of the metastasis was $35 \mathrm{~mm}$ (range 10 $130 \mathrm{~mm}$ ). Median follow-up was 41 months (range 1232 months). In the complete study population, median DFS was 28 months (range 1-228 months) with a median OS of 57 months (range 1-232 months) and a 5-year survival of $48.1 \%$. 

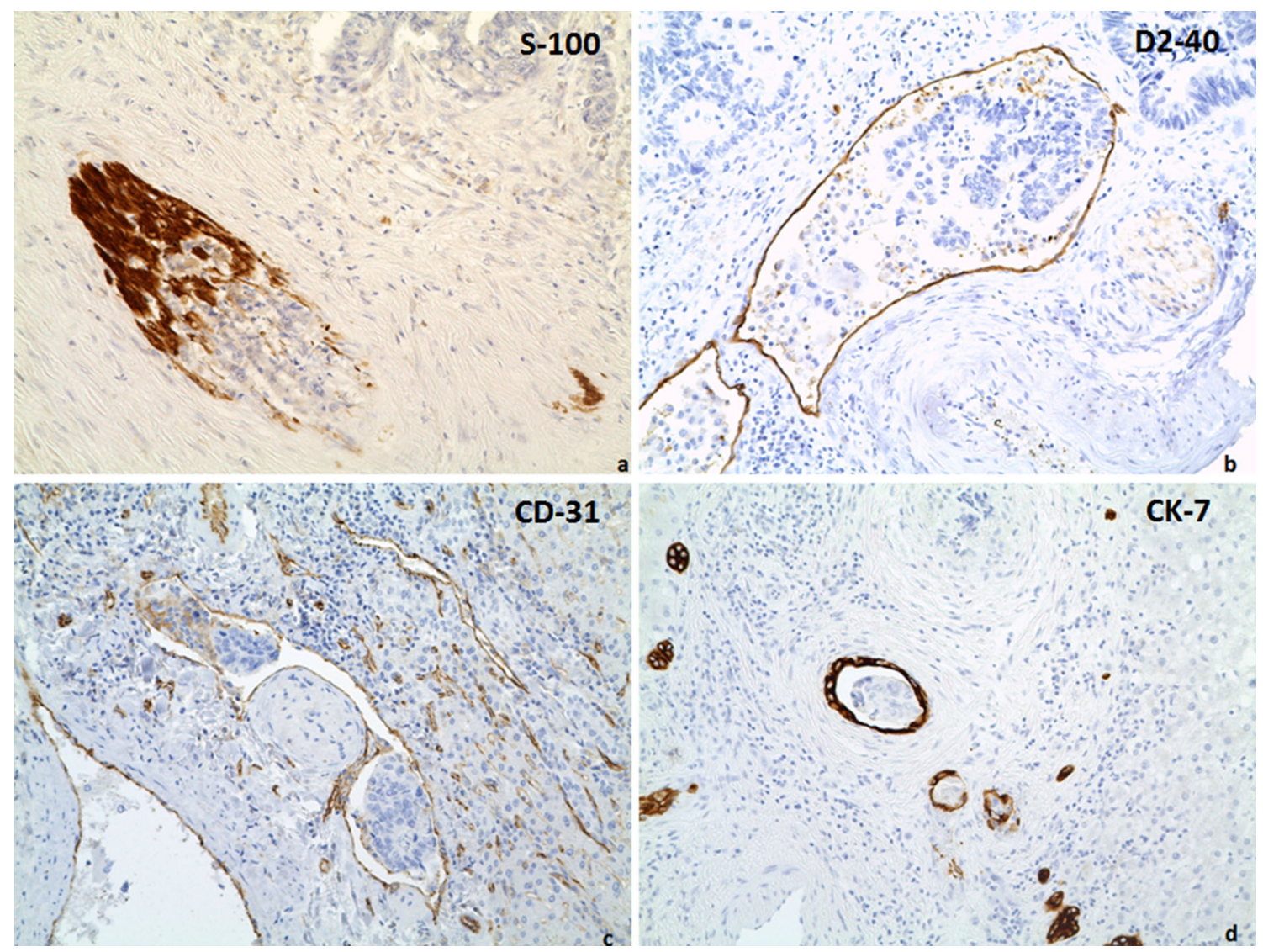

FIG. 3 Different forms of intrahepatic invasion by tumor cells. a Perineural growth showing S-100 reactivity. b Lymphatic invasion showing D2-40 reactivity. c Vascular invasion showing CD-31 reactivity. d Bile duct invasion showing CK-7 reactivity. Original magnification, $\times 20$

\section{Histopathologic Tumor Features}

Fibrous Capsule and Tumor Thickness In $34.4 \%$ of patients $(n=43)$, the liver metastasis was surrounded by a fibrous capsule. Presence of a fibrous capsule was not associated with DFS, but it was associated with an improved OS of 109.3 months, versus 56.7 months in patients without a fibrous capsule $(p=0.037)$. In multivariate analysis, presence of a fibrous capsule was not an independent risk factor for OS (Tables 1, 2).

Tumor thickness at tumor-normal interface varied between 0.1 and $7.2 \mathrm{~mm}$, with a median of $3 \mathrm{~mm}$, and was not correlated with the size of the liver metastases $(p=0.213)$. Although there was a significant association of increased thickness with decreased outcome (both DFS and OS) in univariate analysis, it was no longer significant in multivariate analysis (Tables 1,2).

Intrahepatic Spread Frequency of different forms of intrahepatic invasion varied; perineural growth $(n=11$; $8.9 \%)$ and bile duct invasion $(n=11 ; 8.8 \%)$ were both relatively uncommon, whereas vascular and lymphatic invasion were seen more frequently $(n=46 ; 37.1 \%$, respectively $n=33 ; 26.6 \%$ ).

In univariate analysis, presence of bile duct invasion was associated with improved OS (76.7 vs. 55.9 months; $p=0.048$ ), but this was not the case in multivariate analysis $(p=0.094)$. Presence of intrahepatic lymphatic invasion was correlated with a decreased median OS (41.9 vs. 62.2 months, $p=0.013$ ), which remained significant in multivariate analysis $(p=0.041)$ (Supplementary Fig. 1a).

In the current study, no correlation between different forms of intrahepatic spread or between any of the histologic features and the various items of the clinical risk score was observed. However, there was a correlation between presence of a fibrous capsule and absence of intrahepatic vascular invasion $(p=0.014)$ and between presence of a fibrous capsule and presence of intrahepatic bile duct invasion ( $p=0.013)$.

In 15 patients, a combination of intrahepatic lymphatic invasion and intrahepatic vascular invasion was present, and this combination was associated with a decreased OS (median 28.1 vs. 62.2 months) in univariate and multivariate analysis $(p<0.0001)$ (Supplementary Fig. 1b). 
TABLE 1 Relation of clinical and histologic factors with DFS after liver resection in patients with solitary CRLM

\begin{tabular}{|c|c|c|c|c|c|}
\hline & $n$ & $\%$ & Median DFS & UV $p$ value & MV $p$ value \\
\hline \multicolumn{6}{|l|}{ Size (mm) } \\
\hline$\leq 50$ & 93 & 75 & 50.1 & \multirow[t]{2}{*}{$0.002^{*}$} & \multirow[t]{2}{*}{$0.020^{*}$} \\
\hline$>50$ & 31 & 25 & 14.5 & & \\
\hline \multicolumn{6}{|c|}{ CEA (ng/ml) } \\
\hline$\leq 200$ & 121 & 97.6 & 27.5 & \multirow[t]{2}{*}{0.508} & \multirow[t]{2}{*}{-} \\
\hline$>200$ & 3 & 2.4 & 40.6 & & \\
\hline \multicolumn{6}{|c|}{ DFI (months) } \\
\hline$\leq 12$ & 72 & 58.1 & 27.8 & \multirow[t]{2}{*}{0.232} & \multirow[t]{2}{*}{-} \\
\hline$>12$ & 52 & 41.9 & 25.4 & & \\
\hline \multicolumn{6}{|c|}{ Nodal state primary } \\
\hline No & 54 & 43.5 & 35.7 & \multirow[t]{2}{*}{0.446} & \\
\hline $\mathrm{N}+$ & 70 & 56.5 & 27.5 & & - \\
\hline \multicolumn{6}{|c|}{ Adjuvant therapy } \\
\hline No & 106 & 85.5 & 20.2 & \multirow[t]{2}{*}{$0.013^{*}$} & \multirow[t]{2}{*}{$0.025^{*}$} \\
\hline Yes & 18 & 14.5 & $>50$ & & \\
\hline \multicolumn{6}{|c|}{ Tumor thickness at TNI (mm) } \\
\hline$\leq 3$ & 60 & 48.4 & $>51$ & \multirow[t]{2}{*}{$0.023^{*}$} & \multirow[t]{2}{*}{0.118} \\
\hline$>3$ & 64 & 51.6 & 19.4 & & \\
\hline \multicolumn{6}{|c|}{ Fibrous capsule } \\
\hline Present & 43 & 34.4 & 27.8 & \multirow[t]{2}{*}{0.468} & \multirow[t]{2}{*}{-} \\
\hline Absent & 81 & 65.6 & 25.8 & & \\
\hline \multicolumn{6}{|c|}{ Perineural growth } \\
\hline Present & 11 & 8.9 & 50.2 & \multirow[t]{2}{*}{0.539} & \multirow[t]{2}{*}{-} \\
\hline Absent & 113 & 91.1 & 27.5 & & \\
\hline \multicolumn{6}{|c|}{ Vascular invasion } \\
\hline Present & 46 & 37.1 & 18.0 & \multirow[t]{2}{*}{0.055} & \multirow[t]{2}{*}{0.287} \\
\hline Absent & 78 & 62.9 & 40.8 & & \\
\hline \multicolumn{6}{|c|}{ Lymphatic invasion } \\
\hline Present & 33 & 26.6 & 19.4 & \multirow[t]{2}{*}{0.280} & \multirow[t]{2}{*}{-} \\
\hline Absent & 91 & 73.4 & 29.2 & & \\
\hline Bile duct & & & & & \\
\hline Present & 11 & 8.8 & 27.8 & 0.624 & - \\
\hline Absent & 113 & 91.2 & 27.5 & & \\
\hline
\end{tabular}

$D F S$ disease-free survival, $C R L M$ colorectal liver metastases, $U V$ univariate, $M V$ multivariate, $C E A$ carcinoembryonic antigen, $D F I$ disease-free interval between treatment of primary tumor and detection of the CRLM, TNI tumor-normal interface

$* p<0.05$ was considered statistically significant

\section{DISCUSSION}

The current study describes the association between multiple histologic features in combination with clinical factors and survival in 124 patients who underwent liver resection for CRLM. A homogenous group of patients was evaluated because all patients underwent a complete resection (R0), for a solitary metastasis without neoadjuvant systemic treatment. The only significant histologic factor associated with decreased survival in multivariate analysis was presence of intrahepatic lymphatic invasion, especially in combination with intrahepatic vascular invasion.

Other authors also described lymphatic invasion as a negative predictor for survival. ${ }^{13,18,20}$ In the current study, we observed a relative high frequency of lymphatic invasion $(26.6 \%)$ compared to earlier studies (12$15 \%) .{ }^{18,20}$ This might be due to the use of immunohistochemistry, which is supported by a recently published study with the same methodology and a similar frequency of lymphatic invasion $(29 \%){ }^{18,20,34-36}$ Presence of 
TABLE 2 Relation of clinical and histologic factors with OS after liver resection in patients with solitary CRLM

\begin{tabular}{|c|c|c|c|c|c|}
\hline & $n$ & $\%$ & $\begin{array}{l}\text { Median } \\
\text { OS }\end{array}$ & $\begin{array}{l}\text { UV } p \\
\text { value }\end{array}$ & $\begin{array}{l}\text { MV } p \\
\text { value }\end{array}$ \\
\hline \multicolumn{6}{|c|}{ Size $(\mathrm{mm})$} \\
\hline$\leq 50$ & 93 & 75 & 65.9 & $0.050 *$ & $0.004 *$ \\
\hline$>50$ & 31 & 25 & 29.2 & & \\
\hline \multicolumn{6}{|c|}{ CEA (ng/ml) } \\
\hline$\leq 200$ & 121 & 97.6 & 57.3 & 0.912 & - \\
\hline$>200$ & 3 & 2.4 & 28.9 & & \\
\hline \multicolumn{6}{|l|}{ DFI } \\
\hline$\leq 12$ & 72 & 58.1 & 49.0 & 0.059 & $0.019 *$ \\
\hline$>12$ & 52 & 41.9 & 91.5 & & \\
\hline \multicolumn{6}{|c|}{ Nodal state primary } \\
\hline N0 & 54 & 43.5 & 61.0 & 0.231 & - \\
\hline $\mathrm{N}+$ & 70 & 56.5 & 44.6 & & \\
\hline \multicolumn{6}{|c|}{ Adjuvant therapy } \\
\hline No & 106 & 85.5 & 57.2 & 0.955 & - \\
\hline Yes & 18 & 14.5 & 29.2 & & \\
\hline \multicolumn{6}{|c|}{ Tumor thickness at TNI (mm) } \\
\hline$\leq 3$ & 60 & 48.4 & 95.3 & $0.043 *$ & 0.068 \\
\hline$>3$ & 64 & 51.6 & 48.8 & & \\
\hline \multicolumn{6}{|c|}{ Fibrous capsule } \\
\hline Present & 43 & 34.4 & 109.3 & $0.037 *$ & 0.240 \\
\hline Absent & 81 & 65.6 & 56.7 & & \\
\hline \multicolumn{6}{|c|}{ Perineural growth } \\
\hline Present & 11 & 8.9 & 109.3 & 0.652 & - \\
\hline Absent & 113 & 91.1 & 55.9 & & \\
\hline \multicolumn{6}{|c|}{ Vascular invasion } \\
\hline Present & 46 & 37.1 & 48.8 & 0.483 & - \\
\hline Absent & 78 & 62.9 & 58.2 & & \\
\hline \multicolumn{6}{|c|}{ Lymphatic invasion } \\
\hline Present & 33 & 26.6 & 41.9 & $0.013 *$ & $0.041 *$ \\
\hline Absent & 91 & 73.4 & 62.2 & & \\
\hline \multicolumn{6}{|c|}{ Bile duct invasion } \\
\hline Present & 11 & 8.8 & 76.7 & $0.048^{*}$ & 0.094 \\
\hline Absent & 113 & 91.2 & 55.9 & & \\
\hline
\end{tabular}

$O S$ overall survival, $C R L M$ colorectal liver metastases, $U V$ univariate, $M V$ multivariate, $C E A$ carcinoembryonic antigen, $D F I$ disease-free interval between treatment of primary tumor and detection of the CRLM, TNI tumor-normal interface

$* p<0.05$ was considered statistically significant

lymphatic invasion has been associated with spread to hepatic lymph nodes, which often leads to incurable disease. ${ }^{20,37}$ In the current study, the worse prognosis was demonstrated in patients with a combination of vascular and lymphatic invasion. This unfavorable combination has been observed before and might reflect a tumor with aggressive behavior. ${ }^{23}$
Another interesting finding from the current study was that the median tumor thickness at tumor-normal interface in patients who were not treated with neoadjuvant systemic therapy was $3.0 \mathrm{~mm}$. This was only slightly higher than the tumor thickness of $2.8 \mathrm{~mm}$ described in patients treated with neoadjuvant chemotherapy. ${ }^{26}$ This raises the question whether tumor thickness at tumor-normal interface reflects chemotherapy response or tumor biology; this would be an interesting subject for further research.

A major strength of the present study is the inclusion of patients with solitary CRLM only, who were operated with complete margins (R0) to create an homogenous group of patients. Previous studies on histologic prognostic factors included patients with multiple CRLM and R1 resections as well, which might lead to significant bias of the results. ${ }^{18,20,36}$ First, heterogeneity of histologic features between the different liver metastases might exist and could lead to bias studying prognostic factors for survival. Second, patients who undergo R1 resection usually have a higher risk of local recurrences and have an impaired survival. ${ }^{38,39}$ Third, patients with multiple metastases have a significantly decreased survival, and number of metastases is the most important factor in the Fong classification for survival. ${ }^{9}$ By excluding these potential biases in the present study, the assessment of the prognostic histologic factors are more reliable.

Another strength is that this homogenous group of patients with solitary metastasis were not treated with neoadjuvant systemic therapy. In recent studies, patients with and without neoadjuvant systemic therapy were mixed, and conclusions were drawn from a population highly susceptible to bias. ${ }^{25,36,40}$ Neoadjuvant systemic therapy has a significant impact on tumor histology, and even prognostic factors such as resection margins might be less important. ${ }^{27,28,41}$ Because the detection of histologic prognostic factors in metastatic disease is still in its infancy and the effects of neoadjuvant systemic therapy on lymphatic invasion are unknown, a study with an homogeneous population should be a first step. However, there seems to be an increasing preference to utilize neoadjuvant systemic therapy for high risk patients, despite a lack of convincing evidence on survival benefit in patients with limited metastases. ${ }^{42-44}$ Therefore, a limitation of the present study is that the impact of lymphatic invasion on survival has to be confirmed in patients treated with neoadjuvant systemic therapy. In the total group of patients treated in our institution only 5 patients $(3.8 \%)$ with solitary metastasis were treated with neoadjuvant chemotherapy, which made it impossible to compare, but this should be the goal for future research.

In conclusion, intrahepatic lymphatic invasion, based on immunohistochemical detection of lymphatic vessels, is an adverse prognostic factor for OS in patients with a solitary 
CRLM. Therefore, we recommend evaluating the presence or absence of intrahepatic lymphatic and vascular invasion in the histologic assessment of CRLM. Future research is needed to determine whether adjuvant treatment strategies should be based on these adverse prognostic histologic factors.

ACKNOWLEDGMENT Supported in part by an unrestricted grant of the VALAMO Foundation.

DISCLOSURE The authors declare no conflict of interest.

OPEN ACCESS This article is distributed under the terms of the Creative Commons Attribution 4.0 International License (http:// creativecommons.org/licenses/by/4.0/), which permits unrestricted use, distribution, and reproduction in any medium, provided you give appropriate credit to the original author(s) and the source, provide a link to the Creative Commons license, and indicate if changes were made.

\section{REFERENCES}

1. Jemal A, Bray F, Center MM, et al. Global cancer statistics. $C A$ Cancer J Clin. 2011;61:69-90.

2. Choti MA, Sitzmann JV, Tiburi MF, et al. Trends in long-term survival following liver resection for hepatic colorectal metastases. Ann Surg. 2002;235:759-66.

3. Zakaria S, Donohue JH, Que FG, et al. Hepatic resection for colorectal metastases: value for risk scoring systems? Ann Surg. 2007;246:183-91.

4. House MG, Ito H, Gonen M, et al. Survival after hepatic resection for metastatic colorectal cancer: trends in outcomes for 1,600 patients during two decades at a single institution. $\mathrm{J} \mathrm{Am} \mathrm{Coll}$ Surg. 2010;210:744-5.

5. Hayashi M, Inoue Y, Komeda K, et al. Clinicopathological analysis of recurrence patterns and prognostic factors for survival after hepatectomy for colorectal liver metastasis. BMC Surg. 2010;10:27.

6. Iwatsuki S, Dvorchik I, Madariaga JR, et al. Hepatic resection for metastatic colorectal adenocarcinoma: a proposal of a prognostic scoring system. J Am Coll Surg. 1999;189:291-9.

7. Konopke R, Kersting S, Distler M, et al. Prognostic factors and evaluation of a clinical score for predicting survival after resection of colorectal liver metastases. Liver Int. 2009;29:89-102.

8. Nagashima I, Takada T, Adachi M, et al. Proposal of criteria to select candidates with colorectal liver metastases for hepatic resection: comparison of our scoring system to the positive number of risk factors. World J Gastroenterol. 2006;12:6305-9.

9. Fong Y, Fortner J, Sun RL, et al. Clinical score for predicting recurrence after hepatic resection for metastatic colorectal cancer: analysis of 1001 consecutive cases. Ann Surg. 1999;230:309-18.

10. Shirouzu $\mathrm{K}$, Isomoto $\mathrm{H}$, Kakegawa $\mathrm{T}$, et al. A prospective clinicopathologic study of venous invasion in colorectal cancer. Am J Surg. 1991;162:216-22.

11. Krasna MJ, Flancbaum L, Cody RP, et al. Vascular and neural invasion in colorectal carcinoma. Incidence and prognostic significance. Cancer. 1988;61:1018-23.

12. Benson AB 3rd, Schrag D, Somerfield MR, et al. American Society of Clinical Oncology recommendations on adjuvant chemotherapy for stage II colon cancer. J Clin Oncol. 2004;22:3408-19.
13. Knijn N, de Ridder JA, Punt CJ, et al. Histopathological evaluation of resected colorectal cancer liver metastases: what should be done? Histopathology. 2013;63:149-56.

14. Yamamoto J, Shimada K, Kosuge T, et al. Factors influencing survival of patients undergoing hepatectomy for colorectal metastases. Br J Surg. 1999;86:332-7.

15. Yamamoto J, Sugihara K, Kosuge T, et al. Pathologic support for limited hepatectomy in the treatment of liver metastases from colorectal cancer. Ann Surg. 1995;221:74-8.

16. Tanaka K, Shimada H, Kubota K, et al. Effectiveness of prehepatectomy intra-arterial chemotherapy for multiple bilobar colorectal cancer metastases to the liver: a clinicopathologic study of peritumoral vasculobiliary invasion. Surgery. 2005;137:156-64.

17. Shirabe K, Takenaka K, Gion T, et al. Analysis of prognostic risk factors in hepatic resection for metastatic colorectal carcinoma with special reference to the surgical margin. $\mathrm{Br} J$ Surg. 1997;84:1077-80.

18. Sasaki A, Aramaki M, Kawano K, et al. Prognostic significance of intrahepatic lymphatic invasion in patients with hepatic resection due to metastases from colorectal carcinoma. Cancer. 2002;95:105-11.

19. Okano K, Yamamoto J, Moriya Y, et al. Macroscopic intrabiliary growth of liver metastases from colorectal cancer. Surgery. 1999;126:829-34.

20. Korita PV, Wakai T, Shirai Y, et al. Intrahepatic lymphatic invasion independently predicts poor survival and recurrences after hepatectomy in patients with colorectal carcinoma liver metastases. Ann Surg Oncol. 2007;14:3472-80.

21. Okano K, Maeba T, Moroguchi A, et al. Lymphocytic infiltration surrounding liver metastases from colorectal cancer. J Surg Oncol. 2003;82:28-33.

22. Kubo M, Sakamoto M, Fukushima N, et al. Less aggressive features of colorectal cancer with liver metastases showing macroscopic intrabiliary extension. Pathol Int. 2002;52:514-8.

23. Bockhorn M, Sotiropoulos G, Neuhaus J, et al. Prognostic impact of intrahepatic lymphatic and microvascular involvement in cases of colorectal liver metastases. Int J Colorectal Dis. 2009;24:84550.

24. Okano K, Yamamoto J, Kosuge T, et al. Fibrous pseudocapsule of metastatic liver tumors from colorectal carcinoma. Clinicopathologic study of 152 first resection cases. Cancer. 2000;89:267-75.

25. Brunner SM, Kesselring R, Rubner C, et al. Prognosis according to histochemical analysis of liver metastases removed at liver resection. Br J Surg. 2014;101:1681-91.

26. Maru DM, Kopetz S, Boonsirikamchai P, et al. Tumor thickness at the tumor-normal interface: a novel pathologic indicator of chemotherapy response in hepatic colorectal metastases. Am J Surg Pathol. 2010;34:1287-94.

27. van der Pool AE, Marsman HA, Verheij J, et al. Effect of bevacizumab added preoperatively to oxaliplatin on liver injury and complications after resection of colorectal liver metastases. $J$ Surg Oncol. 2012;106:892-7.

28. Gervaz P, Rubbia-Brandt L, Andres A, et al. Neoadjuvant chemotherapy in patients with stage IV colorectal cancer: a comparison of histological response in liver metastases, primary tumors, and regional lymph nodes. Ann Surg Oncol. 2010;17:2714-9.

29. Loupakis F, Schirripa M, Caparello C, et al. Histopathologic evaluation of liver metastases from colorectal cancer in patients treated with FOLFOXIRI plus bevacizumab. $\mathrm{Br} \mathrm{J}$ Cancer. 2013;108:2549-56.

30. Halama N, Spille A, Lerchl T, et al. Hepatic metastases of colorectal cancer are rather homogeneous but differ from primary 
lesions in terms of immune cell infiltration. Oncoimmunology. 2013;2:e24116.

31. Abengozar M, Fernandez-Acenero MJ, Chaves S, et al. Prognostic utility of tumor thickness at the tumor-normal interface in chemotherapy-treated hepatic colorectal metastasis. Pathol Res Pract. 2012;208:235-9.

32. Brouquet A, Zimmitti G, Kopetz S, et al. Multicenter validation study of pathologic response and tumor thickness at the tumornormal liver interface as independent predictors of disease-free survival after preoperative chemotherapy and surgery for colorectal liver metastases. Cancer. 2013;119:2778-88.

33. Vlems F, van der Worp E, van der Laak J, et al. A study into methodology and application of quantification of tumour vasculature in rectal cancer. Virchows Arch. 2004;445:263-70.

34. Mohammed RA, Martin SG, Gill MS, et al. Improved methods of detection of lymphovascular invasion demonstrate that it is the predominant method of vascular invasion in breast cancer and has important clinical consequences. Am $J$ Surg Pathol. 2007;31:1825-33.

35. Van den Eynden GG, Van der Auwera I, Van Laere SJ, et al. Distinguishing blood and lymph vessel invasion in breast cancer: a prospective immunohistochemical study. $\mathrm{Br} J$ Cancer. 2006;94:1643-9.

36. Lupinacci RM, Mello ES, Pinheiro RS, et al. Intrahepatic lymphatic invasion but not vascular invasion is a major prognostic factor after resection of colorectal cancer liver metastases. World J Surg. 2014;38:2089-96.

37. August DA, Sugarbaker PH, Schneider PD. Lymphatic dissemination of hepatic metastases. Implications for the follow-up and treatment of patients with colorectal cancer. Cancer. 1985;55:1490-4.

38. Angelsen JH, Horn A, Eide GE, et al. Surgery for colorectal liver metastases: the impact of resection margins on recurrence and overall survival. World J Surg Oncol. 2014;12:127.

39. Vigano L, Capussotti L, Lapointe R, et al. Early recurrence after liver resection for colorectal metastases: risk factors, prognosis, and treatment. A LiverMetSurvey-based study of 6,025 patients. Ann Surg Oncol. 2014;21:1276-86.

40. John SK, Robinson SM, Rehman S, et al. Prognostic factors and survival after resection of colorectal liver metastasis in the era of preoperative chemotherapy: an 11-year single-centre study. Dig Surg. 2013;30:293-301.

41. Ayez N, Lalmahomed ZS, Eggermont AM, et al. Outcome of microscopic incomplete resection (R1) of colorectal liver metastases in the era of neoadjuvant chemotherapy. Ann Surg Oncol. 2012;19:1618-27.

42. Nathan H, Bridges JF, Cosgrove DP, et al. Treating patients with colon cancer liver metastasis: a nationwide analysis of therapeutic decision making. Ann Surg Oncol. 2012;19:3668-76.

43. Vauthey JN, Zimmitti G, Kopetz SE, et al. RAS mutation status predicts survival and patterns of recurrence in patients undergoing hepatectomy for colorectal liver metastases. Ann Surg. 2013;258:619-26.

44. Nordlinger B, Sorbye H, Glimelius B, et al. Perioperative FOLFOX4 chemotherapy and surgery versus surgery alone for resectable liver metastases from colorectal cancer (EORTC 40983): long-term results of a randomised, controlled, phase 3 trial. Lancet Oncol. 2013;14:1208-15. 